\title{
Evaluating the psychometric properties of the mental health continuum-short form (MHC-SF) in Dutch adolescents
}

\author{
Chantie C. Luijten ${ }^{1 *} \mathbb{D}$, Sofie Kuppens ${ }^{1,2}$, Daphne van de Bongardt ${ }^{3}$ and Anna P. Nieboer ${ }^{1}$
}

\begin{abstract}
Background: Mental health is increasingly viewed as the presence of various aspects of well-being rather than just the absence of mental illness. The Mental Health Continuum-Short Form (MHC-SF) is a 14-item instrument that assesses mental health, focusing on emotional, psychological, and social well-being. The present study examined for the first time the psychometric properties of the Dutch version of the MHC-SF among adolescents, focusing on its factor structure, internal consistency, construct validity, and gender and age factorial invariance.

Methods: Data were collected from a school-based sample of 1175 adolescents (53.4\% girls) aged 11-17 years $(M=13.7 ; S D=1.1)$. Participants completed an online questionnaire in the classroom during regular school hours. Statistical analyses to evaluate the factor structure, internal consistency, construct validity, and gender and age factorial invariance were performed in SPSS and R.

Results: Using confirmatory factor analyses, a satisfactory-to-good fit was obtained for the three-factor model (emotional, psychological, and social well-being). The MHC-SF scores showed good internal consistency (Cronbach's alpha $=.91)$ and results supported convergent and divergent validity. Finally, the MHC-SF showed gender and age factorial invariance.

Conclusion: The current psychometric evaluation indicates the MHC-SF is a reliable and valid instrument to assess multiple dimensions of well-being among Dutch adolescents. The instrument can be applied for research purposes and in clinical practice.
\end{abstract}

Keywords: Adolescents, Mental health, Well-being, Quality of life outcomes, Psychometric evaluation

\section{Introduction}

Although most adolescents in Western societies develop in a healthy and happy way [1], adolescence remains a period of heightened vulnerability to the onset of mental illness [2]. This vulnerability is related to the substantial physical, emotional, and social transformations that are characteristic of adolescence [3]. This includes the physical and emotional changes associated with maturation, ever-increasing academic expectations, and changing social relationships with family members and peers [1]. Indeed, epidemiological studies of mental illness among adolescents have revealed adolescent mental illness prevalence rates ranging

\footnotetext{
*Correspondence: luijten@eshpm.eur.nl

${ }^{1}$ Erasmus School of Health Policy \& Management, Erasmus University

Rotterdam, Rotterdam, the Netherlands

Full list of author information is available at the end of the article
}

from 10 to $20 \%$ worldwide [4], and a recent study showed that $10 \%$ of Dutch adolescents exhibited signs of mental illness, including mood disorders, anxiety, conduct problems, and substance disorders [5].

Within the literature, mental health and its relation to mental illness have been approached from different perspectives. Traditionally, mental illness has been viewed from a pathology or deficit model, which conceives mental health as the absence of mental illness [6]. However, the sole focus on treatment and prevention of mental illness has not succeeded in reducing the prevalence of mental illness in past decades [7], nor has it prevented early age of onset for mood disorders, anxiety, and substance abuse disorders [8]. A recent meta-analysis revealed that the effectiveness of mental illness treatments for children and adolescents are often modest at best

(c) The Author(s). 2019 Open Access This article is distributed under the terms of the Creative Commons Attribution 4.0 International License (http://creativecommons.org/licenses/by/4.0/), which permits unrestricted use, distribution, and reproduction in any medium, provided you give appropriate credit to the original author(s) and the source, provide a link to the Creative Commons license, and indicate if changes were made. The Creative Commons Public Domain Dedication waiver (http://creativecommons.org/publicdomain/zero/1.0/) applies to the data made available in this article, unless otherwise stated. 
and that efforts to strengthen treatments have not resulted in improved effectiveness over the past five decades [9]. Moreover, adolescents with poor well-being in the absence of mental illness appear to be equally at risk for academic and behaviour problems in school; performing no better than adolescents with a mental illness diagnosis and poor well-being [10].

Therefore, a more positive psychological approach is currently being advocated, which increases the focus on promoting and protecting well-being early in life rather than on preventing and treating deficits, like mental illness symptoms. In line with this approach, the World Health Organisation ([11] p12) defines mental health as "a state of well-being in which every individual realises his or her own potential, can cope with the normal stresses of life, can work productively and fruitfully, and is able to make a contribution to her or his community". According to this definition, mental health is not just the absence of mental illness, but rather reflects the presence of a state of well-being, encompassing life satisfaction, positive emotions, and good functioning in one's individual endeavours and social life.

There is a movement towards integrating symptoms with strengths and considering the balance of risks versus resources [12, 13]. For example, Keyes [14] developed a dual-continuum model, wherein mental illness and well-being are distinct, yet related, continua rather than opposite ends of a single continuum. As such, individuals with a mental illness can still experience high levels of well-being, whereas individuals without a mental illness can still experience low levels of well-being. Indeed, research has shown that an assessment that incorporates both well-being and mental illness symptoms in adolescents was a better predictor of psychosocial functioning, physical health, and school functioning than a unidimensional assessment that only considers mental illness symptoms $[15,16]$.

The concept of well-being itself has also evolved. Historically, well-being has been approached through either a hedonic conception, focusing on, for instance, happiness, positive affect, low negative affect, and satisfaction with life $[17,18]$ or a eudaimonic conception, comprising optimal functioning in one's individual endeavours and social life, such as positive psychological functioning and human development [19-21]. The hedonic tradition is reflected in the conceptualisation of emotional wellbeing in terms of perceptions of avowed happiness and satisfaction with life, and the balance of positive and negative affect over a period of time. It emphasises the subjectivity of experience, including cognitive and affective evaluations of one's life as a whole [22, 23]. The eudaimonic tradition is reflected in the conceptualisation of psychological and social well-being, with a focus on how well individuals see themselves functioning in life (e.g., purpose, personal growth, and positive relationships). Nowadays, well-being is commonly recognised as a multidimensional construct [22], encompassing emotional, psychological, and social well-being, thus, combining the hedonic and eudaimonic traditions [24].

Several instruments have been developed to assess adolescents' well-being, most of which are rather long or measure only one or a few dimensions of well-being. The 14-item Mental Health Continuum-Short Form (MHC-SF) [25] is a relatively brief questionnaire based on the 40-item Mental Health Continuum [26]. It addresses emotional, psychological, and social dimensions of well-being, and can be used to distinguish three levels of well-being: flourishing (i.e., high levels of well-being), moderate (i.e., neither flourishing nor languishing), and languishing (i.e., absence of well-being) [14]. The MHCSF has been shown to have good psychometric properties in both adolescents and adults within various cultural contexts, including Argentina [27], Canada [28], China [29], Egypt [30], India [31], Ireland [32], Italy [33], Korea [34], Poland [35], South Africa [25], and the USA $[36,37]$. In the Netherlands, the MHC-SF has been validated for use with adults [38], but there is not yet a validated Dutch version of the MHC-SF for adolescents.

Therefore, the aim of the present study was to evaluate the psychometric properties of the Dutch version of the MHC-SF in a school-based sample of adolescents. More specifically, the objectives were: 1) to test the factor structure; 2) to examine the internal consistency; 3) to assess the construct validity, including convergent and divergent validity indices; and 4) to examine gender and age invariance of the factor structure of the MHC-SF.

In light of prior findings in adolescent samples [28-32, 34, 35] and Dutch adults [38], the factor structure of the MHC-SF was expected to confirm the three-factor structure of emotional, psychological, and social well-being. Additionally, scores of the MHC-SF subscales were hypothesised to have an adequate internal consistency and the total scores were expected to correlate positively with other measures of well-being, thereby underpinning convergent validity $[29,30,32,35,36,38]$. More specifically, correlations were expected to be moderate-tohigh because the dimensions of the MHC-SF subscales are similar, albeit not identical, to the validity measures [29]. In contrast, the MHC-SF total scores were expected to correlate negatively with measures of mental illness symptoms thereby supporting divergent validity and the dual-continuum model $[28-30,35,36]$. These correlations were expected to be low-to-moderate because they measure distinct, yet related continua, in line with the dual-continuum model perspective $[29,38]$. Finally, the emotional, psychological, and social well-being dimensions were expected to show measurement invariance across gender and age groups [28, 29, 35]. 


\section{Methods \\ Sample}

Adolescents from four secondary schools located in the areas of two large cities in the Netherlands (Amsterdam and Rotterdam) participated in the present study. The sample consisted of 1175 adolescents, including 374 7th graders (31.8\%), 372 8th graders (31.7\%), and 429 9th graders (36.5\%) between 11.0 and 17.0 years old $(\mathrm{M}=$ 13.7, $\mathrm{SD}=1.1)$. The sample included 53.4\% $(n=627)$ girls. The Dutch secondary education system encompasses different levels, including pre-vocational education (VMBO), senior general education (HAVO), and pre-university education (VWO) tracks. Most of the participants $(72.8 \%)$ were enrolled in the HAVO and VWO (higher education) tracks, compared to $27.2 \%$ who were enrolled in the VMBO (lower education) track.

Almost half of the participants (49.1\%) had a Dutch ethno-cultural background (i.e., adolescents and their parents were born in the Netherlands), while $42.1 \%$ had a non-Western ethno-cultural background (i.e., being born or having at least one parent born in an African, Middle Eastern, Asian, or South-American country), and 8.5\% had a non-Dutch Western ethno-cultural background (being born or having at least one parent born elsewhere in Europe or in the USA, Canada, Australia, or New Zealand). Almost three-quarters of the participants (72.8\%) lived with both parents in the same household.

\section{Procedure}

Eligible schools in the Rotterdam and Amsterdam metropolitan areas were approached with an information letter and then contacted by phone and/or email one week later. Four schools provided active informed consent for their students' participation, after which 7th, 8th, and 9th graders and their parents received online information letters describing the aims and procedure of the study. Parents had the opportunity to decline their child's participation (passive informed consent) and adolescents were free to verbally decline participation at any the time during the study. In total, $5.8 \%$ of the parents and $0.4 \%$ of the adolescents declined participation.

Participants completed an online questionnaire in the classroom during regular school hours. Data collection was supervised by the lead researcher and several research assistants, who introduced the study and the procedure, answered questions, ensured maximum privacy, and guaranteed confidentiality of the responses. After completing the questionnaire, participants received small, non-financial incentives and a card with a list of websites to find more information about topics in the questionnaire (e.g., adolescent development, mental health) as well as the contact information of the research team to ask questions. After the data collection phase, one iPhone per school and one gift card per class $(€ 5-€ 7.50$ for 7 th graders, $€ 10$ for 8 th and 9th graders) were raffled.

The medical ethics committee of Erasmus Medical Centre, Rotterdam, the Netherlands determined that the rules stipulated in the Medical Research Involving $\mathrm{Hu}$ man Subjects Act did not apply to this study (protocol no. MEC-2018-055).

\section{Measures \\ MHC-SF}

We used the Dutch version of the MHC-SF [14], which has previously been validated by Lamers et al. [38] in an adult sample. The original English MHC-SF [25] for adolescents is similar to the adult version, with only one adaptation to fit the adolescent population. In particular, examples of community in the item "How often did you feel that you belonged to a community?" were changed from "(like a social group, your neighbourhood, or your city)" to "(like a group of friends, at school, or in the neighbourhood)". In the present study, we used the same adaptation for adolescents in our Dutch version.

The MHC-SF [14] consists of 14 items. Participants were instructed to think about the past month and rated the items on a 6-point scale $(0=$ never, $5=$ every day). The items measure the degree of emotional well-being (items 1-3, e.g., "How often did you feel happy?") in terms of satisfaction with life and the balance between positive and negative affect; psychological well-being (items 9-14, e.g., "How often did you feel good at managing the responsibilities of your daily life?") based on Ryff's model [20, 21]; and social well-being (items 4-8, e.g., "How often did you feel that you had something important to contribute to society?"), focusing on social acceptance, social actualisation, social contribution, social coherence, and social integration [39]. Total sum scores on the MHC-SF can range from 0 to 70, with higher scores indicating higher levels of well-being.

The MHC-SF item scores were also used to distinguish three subgroups: flourishing, moderate, and languishing. In line with previous research, participants who answered "every day" or "almost every day" at least once in the emotional well-being scale and at least 6 times across 11 items measuring social and psychological well-being were diagnosed with flourishing. Participants who "never" or "once or twice" experienced for at least 1 item from the emotional well-being scale and at least 6 items on the social and/or psychological well-being scales were diagnosed with languishing. The respondents classified neither as flourishing nor as languishing are moderately mentally healthy [14].

\section{Other well-being measures}

The participants completed four additional measures of well-being, including the Positive and Negative Affect 
Scale for Children (PANAS-C), the Kidscreen-27, the Social Production Function Instrument for the Level of well-being-short (SPF-ILs), and Cantril's ladder.

PANAS-C The positive affect (PA) dimension of the 10item PANAS-C [40] was selected to measure emotional well-being, as reflected by the extent to which a person feels enthusiastic and active. The PA dimension was assessed by five items: joyful, cheerful, happy, lively, and proud. Participants rated the frequency of PA emotions on a 5 -point scale $(1=$ very little, $5=a$ lot $)$, which were summed to yield a total score. The PA dimension has been shown to measure PA markers well among 6-18year-olds [40]. In the present study, the Cronbach's alpha of the PANAS-C scores was .72.

Kidscreen-2 The Kidscreen-27 [41, 42] is a well-being measure for young children and adolescents focused on life satisfaction, positive emotions, and feeling emotionally balanced. It consists of 27 items (e.g., "Has your life been enjoyable?"; "Have you had fun?"; "Have you felt so bad that you did not want to do anything?"). Participants were instructed to answer the questions in relation to the previous week on a 5-point Likert-type scale from $1=$ poor to $5=$ excellent; or from $1=$ not at all to $5=$ ex tremely; or from $1=$ never to $5=$ always. Four negatively formulated items were recoded according to standard procedures, after which the items were summed to yield a total score. The Kidscreen-27 has been validated with 8-18-year-olds in multiple countries, including the Netherlands [42]. The Cronbach's alpha for the Kidscreen-27 scores in the present study was .92 .

SPF-ILs The SPF-ILs [43] was used to assess the extent to which adolescents' needs for affection, behavioural confirmation, status, comfort, and stimulation are being met. This instrument was selected for validation purposes, because it measures overall well-being in terms of firstorder goals that enable individuals to realise well-being. It consists of 15 items (e.g., "Do you really enjoy your activities?"; "Do you feel useful to others?"). Participants were instructed to think about the past months and rated the items on a 4 -point scale $(1=$ never, $4=$ always $)$. Higher mean scores indicated higher levels of well-being. An adjusted version of the instrument is being used in the ongoing TRAILS (TRacking Adolescents' Individual Lives Survey) study of adolescents and has been shown to have good reliability [44]. In the present study, the Cronbach's alpha of the SPF-ILs scores was .86.

Cantril's ladder Cantril's ladder [45] was used to assess current life satisfaction and reflects a general, cognitive evaluation of a person's well-being. Respondents were asked with a single question to grade their lives on a scale from 0 to 10 with higher scores indicating higher levels of life satisfaction. Cantril's ladder is used worldwide and has been validated among adolescents in Scotland [46].

\section{Mental illness symptoms measures}

RCADS-25 Mental illness symptoms were assessed with the Revised Child Anxiety and Depression Scale-25 (RCADS-25) [47]. The RCADS-25 is a 25-item inventory with 10 items designed to measure depressive symptoms (e.g., "Nothing is much fun anymore") and 15 items designed to measure anxiety symptoms (e.g., "I worry about things"). The items follow a 4-point scale $(0=$ never, $3=$ always), which are summed to yield a total score; with higher scores indicating more severe depression and anxiety. The RCADS-25 was developed for 8 18-year-old respondents and prior research supported internal consistency in a school-based and clinicreferred juvenile sample [47]. In the present study, we obtained Cronbach's alphas of .85 for scores of the depressive symptoms subscale and .84 for the anxiety symptoms subscale.

\section{xStatistical analyses}

Data were analysed using the Statistical Package for the Social Sciences (SPSS) version 23 [48] and R (version 3.4.3) [49] with the lavaan package [50]. The significance level was set at 5.0\% $(p \leq .05)$.

The analyses were conducted in five steps. First, missing value analysis in SPSS indicated that $0.3-0.9 \%$ of the MHC-SF item scores were missing, largely as a consequence of the fact that not all participants fully completed the online questionnaire. Little's test showed that the values were missing completely at random, $X^{2}$ $(131)=111.11, p=.895$. Using the lavaan package, $R$ works with full information maximum likelihood (FIML) and, thus, uses all available information.

Second, confirmatory factor analysis (CFA) was performed in $\mathrm{R}$ to assess the factor structure of the MHCSF. Based on previous empirical research and theoretical considerations, three conceptual models were tested: 1) a single factor model representing general, global wellbeing; 2) a two-factor model comprising one latent factor representing hedonic (i.e., emotional) well-being and one factor representing eudaimonic (i.e., psychological and social) well-being; and 3) a three-factor model reflecting emotional, psychological, and social wellbeing. The CFA models were fitted by robust maximum likelihood (MLR) estimation because simulation studies have shown that the relative bias in parameter estimates was generally negligible, regardless of the number of ordinal categories and the shape of the observed distributions [51-53]. MLR estimation provides a test statistic 
that is asymptotically equivalent to the Yuan-Bentler T2 test statistic [54] with standard errors that are robust against violations of multivariate normality.

Satorra-Bentler $(\mathrm{SB}) \mathrm{X}^{2}$ tests were used to evaluate the absolute fit of the three models. However, because the SB $x^{2}$ test is considered highly conservative, potentially leading to model rejection due to very small model misspecifications in large samples [55], the following alternative indices were also used to evaluate absolute model fit: root mean square error of approximation (RMSEA) [56], comparative fit index (CFI) [57], and standardised root mean square residual (SRMR) [57]. Values of RSMEA $<.06$, CFI $>.95$, and SRMR $\leq .08$ indicated a good model fit, whereas RSMEA $<.08$ and CFI $>.90$ indicated a satisfactory fit $[57,58]$. As we used MLR estimation, Satorra-Bentler (SB) $X^{2}$ tests were used to evaluate the absolute fit of the three models.

Third, Cronbach's alpha was used to examine the internal consistency of the MHC-SF in SPSS. A coefficient $>.70$ indicated good internal consistency [59]. Fourth, Pearson correlations were used to examine the construct validity of the MHC-SF in terms of convergent validity relative to alternative measures of well-being (the PA scale of the PANAS-C, Kidscreen27, SPF-ILs, and Cantril's ladder), as well as divergent validity relative to the RCADS- 25 mental illness symptoms assessment tool. Correlations in the range of .10-.29 were considered low, those in the range of $.30-.49$ were considered moderate, and those $\geq .50$ were considered high [60].

In the fifth and final step, gender and age invariance of the best-fitting MHC-SF factor model were examined in multigroup confirmatory factor analysis. We tested configural invariance (Is the configuration of the model the same across groups?), metric/weak invariance (Are factor loadings the same across groups?), scalar/strong invariance (Are the intercepts the same across groups?), and strict invariance (Are the residual variances the same across groups?) across gender (boys vs girls) and grades (7th vs 8th vs 9th). Configural invariance was confirmed if RSMEA and SRMR were $<.08$ and CFA was $>.95$ [61]. A relative change of $\leq .010$ in CFI, supplemented by a relative change of $\leq .015$ in RMSEA or $\leq .030$ in SRMR indicated that the null hypothesis of invariance should not be rejected [62].

\section{Results}

\section{Factor structure}

Table 1 presents the CFA fit indices for the three models. Model 1 and Model 2, representing a one-factor and twofactor structure, respectively, were found to have a poor absolute fit. The hypothesised three-factor model (Model 3) fitted the data significantly better than Model 1 $\left(\Delta \chi^{2}(3)=220.96, p<.001\right)$ and Model $2\left(\Delta X^{2}(2)=126.97\right.$, $p<.001)$. All items had statisticially significant $(p<.05)$ loadings on their expected factors (i.e., emotional, psychological, and social well-being), as presented in Table 2, and the fit of Model 3 was satisfactory to good.

\section{Descriptive characteristics}

Descriptive results and Pearson correlation coefficients of the MHC-SF total, subscale and item scores are presented in Table 3. Based on the three mental health categories, a majority of the participants $(n=638,54.3 \%)$ experienced flourishing levels of well-being, followed by moderate levels, $(n=475,40.4 \%)$, with relatively few reporting a languishing level $(n=62,5.3 \%)$.

\section{Internal consistency}

Internal consistency testing of scores of the MHC-SF total scale and subscales based on Model 3 yielded the following Cronbach's alpha values: emotional well-being subscale, $\alpha=.80$; psychological well-being subscale, $\alpha=.83$; social well-being subscale, $\alpha=.81$; and total MHC-SF, $\alpha=.91$.

\section{Construct validity}

The correlations of MHC-SF and the corresponding validation measures of well-being and mental illness symptoms are reported in Table 4. We observed significant positive correlations of MHC-SF scores with the PANAS-C, Kidscreen-27, SPF-ILs, and Cantril's ladder validation measures, confirming convergent validity. Most of the correlations were high in magnitude and a few were moderate. In addition, significant negative correlations, mostly of moderate strength, were found between the MHC-SF and the RCADS-25 mental illness symptoms measure. These results supported divergent validity.

\section{Measurement invariance}

The multigroup confirmatory factor analysis results are presented in Table 5. The three-factor model (Model 3)

Table 1 Results of the Confirmatory Factor Analyses

\begin{tabular}{|c|c|c|c|c|c|c|c|}
\hline Model & $S B x^{2}$ & $\mathrm{df}$ & $p$ & RMSEA & $90 \%$ CI RMSEA & $\mathrm{CFI}$ & SRMR \\
\hline 1. One factor & 789.09 & 77 & $<.001$ & .089 & $.085-.094$ & .861 & .057 \\
\hline 2. Two factors & 602.77 & 76 & $<.001$ & .077 & $.072-.082$ & .897 & .052 \\
\hline 3. Three factors & 451.19 & 74 & $<.001$ & .066 & $.061-.071$ & .927 & .052 \\
\hline
\end{tabular}

Notes. $S B X^{2}$ Santorra-Bentler Chi Squared test, $d f$ degrees of freedom, $C l$ confidence interval, RMSEA root mean square error of approximation, $C F I$ comparative fit index, SRMR standardised root mean square residual. Criteria for interpreting model fit are: $\mathrm{RSMEA}<.08, \mathrm{CFI}>.90$, and SRMR $\leq .08$ 
Table 2 Descriptive Characteristics and Factor Loadings of the MHC-SF Items

\begin{tabular}{|c|c|c|c|c|c|}
\hline \multirow[t]{2}{*}{ In the past month, how often did you feel... } & \multirow[t]{2}{*}{ Median } & \multirow{2}{*}{$\begin{array}{l}\text { Missing } \\
(\%)\end{array}$} & \multicolumn{3}{|c|}{ Factor loadings (Model 3) } \\
\hline & & & $\begin{array}{l}\text { Emotional well- } \\
\text { being }\end{array}$ & $\begin{array}{l}\text { Psychological } \\
\text { well-being }\end{array}$ & $\begin{array}{l}\text { Social well- } \\
\text { being }\end{array}$ \\
\hline \multicolumn{6}{|l|}{ Emotional well-being } \\
\hline 1. Happy & 4.00 & $0.3 \%$ & .78 & & \\
\hline 2. Interested in life & 4.00 & $0.5 \%$ & .72 & & \\
\hline 3. Satisfied & 4.00 & $0.3 \%$ & .79 & & \\
\hline \multicolumn{6}{|l|}{ Social well-being } \\
\hline 4. That you had something important to contribute to society & 3.00 & $0.5 \%$ & & & .66 \\
\hline $\begin{array}{l}\text { 5. That you belonged to a community (like a group of friends, at school or } \\
\text { in the neighbourhood) }\end{array}$ & 5.00 & $0.4 \%$ & & & .49 \\
\hline 6. That our society is becoming a better place for people & 2.00 & $0.6 \%$ & & & .78 \\
\hline 7. That people are basically good & 3.00 & $0.5 \%$ & & & .79 \\
\hline 8. That the way our society works makes sense to you & 3.00 & $0.5 \%$ & & & .71 \\
\hline \multicolumn{6}{|l|}{ Psychological well-being } \\
\hline 9. That you liked most parts of your personality & 4.00 & $0.6 \%$ & & .78 & \\
\hline 10. Good at managing the responsibilities of your daily life & 4.00 & $0.6 \%$ & & .69 & \\
\hline 11. That you had warm and trusting relationships with others & 4.00 & $0.8 \%$ & & .62 & \\
\hline $\begin{array}{l}\text { 12. That you have experiences that challenge you to grow and become a } \\
\text { better person }\end{array}$ & 3.00 & $0.9 \%$ & & .47 & \\
\hline 13. Confident to think or express your own ideas and opinions & 4.00 & $0.7 \%$ & & .72 & \\
\hline 14. That your life has a sense of direction or meaning to it & 4.00 & $0.8 \%$ & & .75 & \\
\hline
\end{tabular}

fitted the data satisfactorily across genders and grades, indicating that configural invariance was supported. Hereafter, equality constraints were imposed on all factor loadings for both gender and all grade groups. The $\triangle \mathrm{CFI}, \triangle \mathrm{RSMEA}$, and $\triangle \mathrm{SRMR}$ indicated full metric invariance $(<.01)$. Equality constraints were then imposed on all intercepts and the three difference tests also indicated full scalar invariance. Finally, equality constraints were imposed on all residual variances, with the $\triangle \mathrm{CFI}$, $\triangle \mathrm{RSMEA}$, and $\triangle \mathrm{SRMR}$ supporting full strict invariance.

\section{Discussion}

To evaluate the psychometric properties of the Dutch version of the MHC-SF in a school-based sample of adolescents, we tested the factor structure and invariance and assessed internal consistency and construct validity of the MHC-SF. All items loaded significantly on their expected factors, consistent with prior research in adolescents [28-32, 34, 35] and in Dutch adults [38]. CFAanalyses confirmed the three-factor structure of the MHC-SF. The three-factor model was the best-fitting model to these data, suggesting that the items measuring emotional, psychological, and social well-being are reflections of three distinct but correlated latent factors. The goodness of fit of the three-factor model was satisfactory to good and comparable to, sometimes even better than, results from prior studies in adolescent and adult samples [25, 27-37].

We observed good internal consistency for the MHCSF and, as expected, moderate-to-high associations with well-being validation measures-namely PA of the PANAS-C, Kidscreen-27, SPF-ILs, and Cantril's laddersupporting convergent validity. Some measures, such as the Kidscreen-27 and SPF-ILs, cover a broader

Table 3 Descriptive Statistics and Pearson Correlation Coefficients of the MHC-SF Subscales

\begin{tabular}{lllll}
\hline Dimension & Emotional well-being & Psychological well-being & Social well-being & MHC-SF Total \\
\hline M (SD) & $3.88(0.94)$ & $3.47(1.08)$ & $-93(1.19)$ & $-.60^{* * *}$ \\
Emotional well-being & - & $-.70^{* * *}$ & $.70^{* * *}$ \\
Psychological well-being & $.63^{* * *}$ & - & - \\
Social well-being & $.60^{* * *}$ & $.74^{* * *}$ & -
\end{tabular}

Notes: Correlations for girls are presented above the diagonal and correlations for boys below the diagonal 
Table 4 Pearson Correlation Coefficients for Construct Validity

\begin{tabular}{|c|c|c|c|c|}
\hline \multirow[t]{2}{*}{ Instrument } & \multicolumn{3}{|c|}{ MHC-SF well-being dimension subscale } & \multirow{2}{*}{$\begin{array}{l}\text { MHC- } \\
\text { SF } \\
\text { total }\end{array}$} \\
\hline & Emotional & Psychological & Social & \\
\hline \multicolumn{5}{|l|}{ Convergent validity } \\
\hline PA of PANAS-C & $.58^{* * *}$ & $.52^{* * *}$ & $.45^{* * *}$ & $.56^{* * *}$ \\
\hline Kidscreen-27 & $.67^{* * *}$ & $.55^{* * *}$ & $.50^{* * *}$ & $.62^{* * *}$ \\
\hline SPF-ILS & $.62^{* * *}$ & $.65^{* * *}$ & $.55^{* * *}$ & $.68^{* * *}$ \\
\hline Cantril's ladder & $.58^{* * *}$ & $.44^{* * *}$ & $.39^{* * *}$ & $.50^{* * *}$ \\
\hline \multicolumn{5}{|l|}{ Divergent validity } \\
\hline RCADS-25 & $-.51^{* * *}$ & $-.46^{* * *}$ & $-.41^{* * *}$ & $-.50^{* * *}$ \\
\hline Depression & $-.55^{* * *}$ & $-.48^{* * *}$ & $-.43^{* * *}$ & $-.53^{* * *}$ \\
\hline Anxiety & $-.41^{* * *}$ & $-.38^{* * *}$ & $-.34^{* * *}$ & $-.41^{* * *}$ \\
\hline
\end{tabular}

conceptualisation of well-being than others like the PANAS-C and Cantril's ladder. The well-being validation measure SPF-Ils, for example, correlated strongest with total MHC-SF score, an assessment of overall wellbeing. This result is not surprising given that the SPFILs is used as an overall well-being measure encompassing social and physical well-being subdimensions. On the other hand, the PANAS-C and Cantril's ladder instruments are more specific measures of emotional well-being and life satisfaction and indeed correlated strongest with the MHC-SF emotional well-being subscale. Thus, the MHC-SF is a reliable and valid instrument to assess well-being of adolescents.

The mostly moderate associations of the MHC-SF with mental illness symptoms (i.e., anxiety and depression symptoms) supported divergent validity. Previous studies involving adolescents and Dutch adults have also shown divergent validity of the MHC-SF vis-à-vis correlations with anxiety and depression symptoms $[25,31,33-35,38]$. Consistent with the dual-continuum model, in which mental health and mental illness are conceptualised as two distinct, yet related continua, our results showed correlations between mental health and mental illness symptoms measures, with some divergence. The correlations were weaker compared to the correlations with the well-being validation measures, but still significant. This indicates that the absence of mental illness does not necessarily imply the presence of well-being and emphasises the importance of a positive psychological approach in the assessment of mental health.

Finally, full strict invariance was observed by gender and grade. The MHC-SF structure, factor loadings, intercepts, and residual variances were the same in boys and girls, and also the same across different age groups, in line with our expectations based on recent studies $[28,29,33,35]$. These findings indicate that the MHCSF measures well-being with the same level of accuracy in boys and girls and with the same level of accuracy across different age groups, which supports broad usage of the MHC-SF to measure well-being in adolescent populations.

\section{Limitations and future research directions}

Although this study was strengthened by the use of a large sample of Dutch adolescents $(N=1175)$, the national generalisability of our results may have been compromised by our use of a school-based sample. To examine the representativeness of this sample, a comparison was made to the Health Behaviour in School-age Children (HBSC) study, where the sample is considered to be representative of the general Dutch adolescent population [63]. This comparison showed that our sample may be considered representative with respect to gender, age, and household characteristic variances. However, it differed from the HBSC study regarding

Table 5 Measurement Invariance across Gender and Grades (Model 3)

\begin{tabular}{|c|c|c|c|c|c|c|c|c|}
\hline Model & $S B x^{2}$ & $\mathrm{df}$ & RMSEA & $\triangle$ RMSEA & $\mathrm{CFI}$ & $\Delta \mathrm{CFI}$ & SRMR & $\triangle S R M R$ \\
\hline \multicolumn{9}{|c|}{ Gender invariance } \\
\hline 1. Configural & 735.84 & 148 & .083 & - & .919 & - & .053 & - \\
\hline 2. Metric & 750.37 & 159 & .080 & .003 & .919 & .000 & .055 & .002 \\
\hline 3. Scalar & 806.59 & 170 & .080 & .000 & .913 & .006 & .059 & .004 \\
\hline 4. Strict & 845.14 & 184 & .079 & .001 & .909 & .004 & .060 & .001 \\
\hline \multicolumn{9}{|l|}{ Grade invariance } \\
\hline 1. Configural & 806.67 & 222 & .083 & - & .921 & - & .055 & - \\
\hline 2. Metric & 826.44 & 244 & .079 & .004 & .921 & .000 & .059 & .004 \\
\hline 3. Scalar & 872.13 & 266 & .077 & .002 & .918 & .003 & .061 & .002 \\
\hline 4. Strict & 956.77 & 294 & .076 & .001 & .910 & .008 & .064 & .003 \\
\hline
\end{tabular}

Notes. $S B X^{2}$ Santorra-Bentler Chi Squared test, $d f$ degrees of freedom, $C l$ confidence interval, RMSEA root mean square error of approximation, $C F I$ comparative fit index, SRMR standardised root mean square residual. Criteria for interpreting model fit are: $\mathrm{RSMEA}<.08, \mathrm{CFI}>.90$, and $\mathrm{SRMR} \leq .08$ 
ethnicity and education level in that our cohort had over-representations of participants with a non-Western ethno-cultural background (42\% vs. $17 \%)$ and with a high education level ( $73 \%$ vs. $53 \%)$. These differences may be explained by the fact that the four involved schools were located in two relatively diverse metropolitan areas that tend to have more adolescents with a non-Western ethno-cultural background than other, less urban areas in the Netherlands. In addition, the involved schools consisted of more adolescents with a high educational level. The involvement of more schools with diverse educational levels is, therefore, recommended in future research.

Ethnicity and educational level are important determinants of health and well-being [1] and, therefore, the over-representations of a non-Western ethno-cultural background and high education level may have biased our results. However, in accordance with Dutch adolescents being among the happiest and most satisfied with their lives around the world [63], the percentage of flourishing adolescents (54.3\%) in this study was much higher than the percentages reported for other adolescent samples (23.4\% in Egypt [30]; 11.7\% in Korea [34]).

Furthermore, it should be noted that our data were hierarchical in nature with students nested in grades and schools. When we evaluated the necessity of using multilevel models, we found some variance at level of grade, but not of school. This variance was, however, fairly small and did not affect our conclusions (data available upon request). Consequently, we performed our analyses without accounting for the nested structure.

It is recommended that, in addition to emotional, psychological, and social well-being, a dimension of physical well-being be included in future research to assess adolescents' overall well-being. Keyes' dual-continuum model and the MHC-SF focus on emotional, psychological, and social well-being as positive mental health. However, there is consensus that mental and physical health are deeply interdependent [64]. Moreover, the MHC-SF includes only positive items to measure well-being even though the dual-continuum model proposes that well-being can be achieved even when there are negativities such as mental illness or feelings of negative affect like sadness. Negative aspects of well-being are likely to be relevant for social and psychological well-being, especially with respect to troubled social relationships or social dysfunction. Finally, future studies are needed to validate the MHC-SF in clinical adolescent populations and to perform cross-country comparisons of measurement invariance.

\section{Conclusion}

This is the first study to evaluate psychometric properties of the Dutch version of the MHC-SF in an adolescent sample. The results indicated that the MHC-SF is a valid and reliable instrument that can be administered to assess different dimensions of well-being in adolescents across mental health, education, and health policy contexts. The brevity of the MHC-SF (14 items) and its cross-contextual utility make it highly suitable for scientific and epidemiological monitoring of adolescent mental health and well-being. It may also provide a useful tool that can be used across interventions and prevention strategies because of the importance to promote and protect well-being in addition to reducing mental illness symptoms. The ability to distinguish among flourishing, moderate, and languishing adolescents creates the possibility to manage multiple dimensions of wellbeing to ensure more complete mental health and to choose and implement interventions that are informed by an individual's position along both the mental illness and well-being dimensions. Ultimately, the ability to properly assess the complexity and multidimensionality of well-being may lead to more effective improvements in adolescent mental health and related developmental outcomes. The present findings enable future comparisons between adolescent samples across countries and contribute to the extensive use of the MHC-SF in research and clinical practice.

\section{Abbreviations \\ CFA: Confirmatory factor analysis; CFI: Comparative fit index; FIML: Full information maximum likelihood; HAVO: Senior general education track; HBSC: Health Behaviour in School-age Children; MHC-SF: Mental Health Continuum-Short Form; MLR: Robust maximum likelihood method; PA: Positive affect; PANAS-C: Positive and Negative Affect Scale for Children; RCADS-25: Revised Child Anxiety and Depression Scale-25; RSMEA: Root mean square error of approximation; SB: Satorra-Bentler; SPF-ILS: Social Production Function Instrument for the Level of well-being scale; SRMR: Standardised root mean square residual; TRAILS: TRacking Adolescents' Individual Lives Survey; VMBO: Pre-vocational education track; WW: \\ Pre-university education track}

\section{Acknowledgements}

We would like to thank Dr. Joran Jongerling (Department of Psychology, Education \& Child Studies; Erasmus University Rotterdam) for the statistical advice for the current study.

\section{Authors' contributions}

$\mathrm{CL}$ and $\mathrm{AN}$ drafted the design for data collection and were involved in subject recruitment and data collection. CL performed the statistical analysis and $C L, S K, D B$, and $A N$ interpreted the data. $C L$ drafted the manuscript and $\mathrm{SK}, \mathrm{DB}$, and $\mathrm{AN}$ contributed to its refinement. All authors read and approved the final manuscript.

\section{Funding}

Not applicable.

\section{Availability of data and materials}

The dataset used and analysed during the current study is available from the corresponding author on reasonable request.

Ethics approval and consent to participate

The medical ethics committee of Erasmus Medical Centre, Rotterdam, the Netherlands determined that the rules stipulated in the Medical Research Involving Human Subjects Act did not apply to this study (protocol no. MEC-2018-055). 


\section{Consent for publication}

Not applicable.

\section{Competing interests}

The authors declare that they have no competing interests.

\section{Author details}

${ }^{1}$ Erasmus School of Health Policy \& Management, Erasmus University Rotterdam, Rotterdam, the Netherlands. ${ }^{2}$ Centre for Environment and Health, Department of Public Health and Primary Care, KU Leuven, Leuven, Belgium. ${ }^{3}$ Department of Psychology, Education \& Child Studies, Erasmus University Rotterdam, Rotterdam, the Netherlands.

Received: 14 June 2019 Accepted: 20 September 2019

\section{Published online: 22 October 2019}

\section{References}

1. Inchley J, Currie D, Young T, Samdal O, Torsheim T, Augustson L, et al. Growing up unequal: gender and socioeconomic differences in young people's health and well-being. Health Behaviour in School-aged Children (HBSC) study: international report from the 2013/2014 survey. Copenhagen, Denmark: WHO Regional Office for Europe; 2016. 277 p. (Health Policy for Children and Adolescents; 7).

2. Paus T, Keshavan M, Giedd JN. Why do many psychiatric disorders emerge during adolescence? Nat Rev Neurosci. 2008:9:947-57.

3. Blakemore S. The social brain in adolescence. Nat Rev Neurosci. 2008;9:267-77.

4. Kieling C, Baker-Henningham H, Belfer M, Conti G, Ertem I, Omigbodun O, et al. Child and adolescent mental health worldwide: evidence for action. Lancet. 2011;378:1515-25.

5. Ormel J, Raven D, van Oort F, Hartman C, Reijneveld S, Veenstra R, et al. Mental health in Dutch adolescents: a TRAILS report on prevalence, severity, age of onset, continuity and co-morbidity of DSM disorders. Psychol Med. 2015:45:345-60.

6. Snyder CR, Lopez SJ. Handbook of positive psychology. Eds. New York: Oxford University Press; 2002.

7. Insel T, Scolnick E. Cure therapeutics and strategic prevention: raising the bar for mental health research. Mol Psychiatry. 2006;11:11-7.

8. Kessler RC, Berglund P, Demler O, Jin R, Merikangas KR, Walters EE. Lifetime prevalence and age-of-onset distributions of DSM-IV disorders in the National Comorbidity Survey Replication. Arch Gen Psychiatry. 2005;62:593-602.

9. Weisz JR, Kuppens S, Ng MY, Eckshtain D, Ugueto AM, Vaughn-Coaxum R, et al. What five decades of research tells us about the effects of youth psychological therapy: a multilevel meta-analysis and implications for science and practice. Am Psychol. 2017;72:79-117.

10. Antaramian SP, Scott Huebner E, Hills KJ, Valois RF. A dual-factor model of mental health: toward a more comprehensive understanding of youth functioning. Am J Orthopsychiatry. 2010;80:462-72.

11. World Health Organisation. Promoting mental health: concepts, emerging evidence, practice (summary report). Geneva, Switzerland: WHO Press; 2004. p. 69.

12. Peterson C, Seligman ME. Character strengths and virtues: a handbook and classification. Washington, DC: American Psychological Association; 2004.

13. Seligman M. Flourish: positive psychology and positive interventions [PDF] Ann Arbor, Michigan: The University of Michigan; 2010. Available from: https://tannerlectures.utah.edu/_documents/a-to-z/s/Seligman_10.pdf

14. Keyes CL. Mental illness and/or mental health? Investigating axioms of the complete state model of health. J Consult Clin Psychol. 2005;73:539-48.

15. Suldo SM, Shaffer EJ. Looking beyond psychopathology: the dual-factor model of mental health in youth. Sch Psychol Rev. 2008;37:52-68.

16. Suldo SM, Thalji A, Ferron J. Longitudinal academic outcomes predicted by early adolescents' subjective well-being, psychopathology, and mental health status yielded from a dual factor model. J Posit Psychol. 2011;6:17-30.

17. Bradburn N. The structure of psychological well-being. Chicago: Aldine; 1969.

18. Diener E. Subjective well-being. Psychol Bull. 1984;95:542-75.

19. Rogers C. On becoming a person: a therapist's view of psychotherapy. London: Constable \& Company; 1961.

20. Ryff CD. Happiness is everything, or is it? Explorations on the meaning of psychological well-being. J Pers Soc Psychol. 1989;57:1069-81.

21. Ryff CD. Beyond Ponce de Leon and life satisfaction: new directions in quest of successful ageing. Int J Behav Dev. 1989;12:35-55.
22. Diener E. Subjective well-being. In: Diener E, editor. The science of well-being. New York: Springer; 2009. p. 11-58.

23. Kahneman D, Diener E, Schwarz N, editors. Well-being: foundations of hedonic psychology. New York: Russell Sage Foundation; 1999.

24. Gallagher MW, Lopez SJ, Preacher KJ. The hierarchical structure of well-being. J Pers. 2009;77:1025-50.

25. Keyes $\mathrm{CL}$, Wissing M, Potgieter JP, Temane M, Kruger A, Van Rooy S. Evaluation of the mental health continuum-short form (MHC-SF) in setswana-speaking south Africans. Clin Psychol Psychother. 2008;15:181-92.

26. Keyes $\mathrm{CL}$. The mental health continuum: from languishing to flourishing in life. J Health Soc Behav. 2002:43:207-22.

27. Perugini MLL, de la Iglesia G, Solano AC, Keyes CL. The mental health continuum-short form (MHC-SF) in the Argentinean context: confirmatory factor analysis and measurement invariance. Eur J Psychol. 2017;13:93-108.

28. Doré I, O'Loughlin JL, Sabiston CM, Fournier L. Psychometric evaluation of the mental health continuum-short form in French Canadian Young adults. Can J Psychiatry. 2017;62:286-94.

29. Guo C, Tomson G, Guo J, Li X, Keller C, Söderqvist F. Psychometric evaluation of the mental health continuum-short form (MHC-SF) in Chinese adolescents-a methodological study. Health Qual Life Outcomes. 2015:13:198-206.

30. Salama-Younes M. Validation of the mental health continuum short form and subjective vitality scale with Egyptian adolescent athletes. In: Brdar I, editor. The human pursuit of well-being. Dordrecht: Springer; 2011. p. 221-34.

31. Singh K, Bassi M, Junnarkar M, Negri L. Mental health and psychosocial functioning in adolescence: an investigation among Indian students from Delhi. J Adolesc. 2015;39:59-69.

32. Donnelly A, O'Reilly A, Dolphin L, O'Keeffe L, Moore J. Measuring the performance of the mental health continuum-short form (MHC-SF) in a primary care youth mental health service. Ir J Psychol Med. 2019:1-5.

33. Petrillo G, Capone V, Caso D, Keyes CL. The mental health continuum-short form (MHC-SF) as a measure of well-being in the Italian context. Soc Indic Res. 2015;121:291-312

34. Lim YJ. Psychometric characteristics of the Korean mental health continuumshort form in an adolescent sample. J Psychoeduc Assess. 2014;32:356-64.

35. Karaś D, Cieciuch J, Keyes CL. The polish adaptation of the mental health continuum-short form (MHC-SF). Personal Individ Differ. 2014;69:104-9.

36. Keyes $\mathrm{CL}$. The subjective well-being of America's youth: toward a comprehensive assessment. Adolescent Family Health. 2006;4:3-11.

37. Keyes $C L$, Eisenberg D, Perry GS, Dube SR, Kroenke K, Dhingra SS. The relationship of level of positive mental health with current mental disorders in predicting suicidal behavior and academic impairment in college students. J Am Coll Heal. 2012;60:126-33.

38. Lamers SM, Westerhof GJ, Bohlmeijer ET, ten Klooster PM, Keyes CL. Evaluating the psychometric properties of the mental health continuumshort form (MHC-SF). J Clin Psychol. 2011;67:99-110.

39. Keyes CL. Social well-being. Soc Psychol Q. 1998;61:121-40.

40. Ebesutani C, Regan J, Smith A, Reise S, Higa-McMillan C, Chorpita BF. The 10-item positive and negative affect schedule for children, child and parent shortened versions: application of item response theory for more efficient assessment. J Psychopathol Behav Assess. 2012;34:191-203.

41. The Kidscreen Group Europe. The KIDSCREEN questionnaires - quality of life questionnaires for children and adolescents. Handbook Lenge-Rich. 2006.

42. Ravens-Sieberer U, Auquier P, Erhart M, Gosch A, Rajmil L, Bruil J, et al. The KIDSCREEN-27 quality of life measure for children and adolescents: psychometric results from a cross-cultural survey in 13 European countries. Qual Life Res. 2007;16:1347-56.

43. Nieboer A, Lindenberg S, Boomsma A, Bruggen ACV. Dimensions of well-being and their measurement: the SPF-IL scale. Soc Indic Res. 2005;73:313-53.

44. Verboom CE, Sijtsema JJ, Verhulst FC, Penninx BW, Ormel J. Longitudinal associations between depressive problems, academic performance, and social functioning in adolescent boys and girls. Dev Psychol. 2014;50:247-57.

45. Cantril H. Pattern of human concerns. New Brunswick, NJ: Rutgers University Press; 1965

46. Levin K, Currie C. Reliability and validity of an adapted version of the Cantril ladder for use with adolescent samples. Soc Indic Res. 2014;119:1047-63.

47. Ebesutani C, Reise SP, Chorpita BF, Ale C, Regan J, Young J, et al. The revised child anxiety and depression scale-short version: scale reduction via exploratory bifactor modeling of the broad anxiety factor. Psychol Assess. 2012:24:833-45. 
48. IBM Corp. Released 2015. IBM SPSS statistics for windows, version 23.0 Armonk, NY: IBM Corp.

49. R Core Team. R: A language and environment for statistical computing. Vienna, Austria: R Foundation for Statistical Computing; 2017. Available from: https://www.R-project.org/.

50. Lavaan RY. An R package for structural equation modeling and more. Version 0.5-12 (BETA). J Stat Softw. 2012;48:1-36.

51. Lei P. Evaluating estimation methods for ordinal data in structural equation modeling. Qual Quant. 2009;43:495-507.

52. Oranje A. Comparison of estimation methods in factor analysis with categorized variables: applications to NAEP data. Annual meeting of the American Educational Research Association, Chicago, IL; 2003 Apr.

53. Yang-Wallentin $F$, Jöreskog KG, Luo H. Confirmatory factor analysis of ordinal variables with misspecified models. Struct Equ Model. 2010;17:392-423.

54. Yuan KH, Bentler PM. Three likelihood-based methods for mean and covariance structure analysis with nonnormal missing data. Sociol Methodol. 2000;30:165-200.

55. Brown TA. Confirmatory factor analysis for applied research. New York: The Guilford Press; 2006.

56. Steiger JH, Lind JC. Statistically-based tests for the number of common factors. lowa City, IA: Annual meeting of the Psychometric Society; 1980

57. Hu LT, Bentler PM. Cutoff criteria for fit indexes in covariance structure analysis: conventional criteria versus new alternatives. Struct Equ Model Multidiscip J. 1999;6:1-55.

58. Bentler P, Bonett D. Significance tests and goodness of fit in the analysis of covariance structures. Psychol Bull. 1980;88:588-606.

59. Nunnally J, Bersntein I. Psychometric theories. Madrid, Spain: McGraw-Hill; 1995

60. Cohen J. Statistical power analysis for the behavioral sciences. $2^{\text {nd }}$ ed. Hillsdale, NJ: Erlbaum; 1988.

61. Cheung GW, Rensvold RB. Evaluating goodness-of-fit indexes for testing measurement invariance. Struct Equ Model. 2002;9:233-55.

62. Chen FF. Sensitivity of goodness of fit indexes to lack of measurement invariance. Struct Equ Model. 2007;14:464-504.

63. Stevens G, Van Dorsselaer S, Boer M, De Roos S, Duinhog E, Ter Bogt T, et al. HBSC 2017. Gezondheid en welzijn van jongeren in Nederland. Utrecht, the Netherlands: Universiteit Utrecht; 2018. p. 194.

64. McCloughen A, Foster K, Huws-Thomas M, Delgado C. Physical health and wellbeing of emerging and young adults with mental illness: an integrative review of international literature. Int J Ment Health Nurs. 2012;21:274-88.

\section{Publisher's Note}

Springer Nature remains neutral with regard to jurisdictional claims in published maps and institutional affiliations.

Ready to submit your research? Choose BMC and benefit from:

- fast, convenient online submission

- thorough peer review by experienced researchers in your field

- rapid publication on acceptance

- support for research data, including large and complex data types

- gold Open Access which fosters wider collaboration and increased citations

- maximum visibility for your research: over $100 \mathrm{M}$ website views per year

At $\mathrm{BMC}$, research is always in progress.

Learn more biomedcentral.com/submissions 